\title{
Políticas culturais para a capoeira no Brasil: a avaliação dos mestres quanto à participação social
}

Alice Pires de Lacerda ${ }^{1}$

1 Doutora em cultura e sociedade pela Universidade Federal da Bahia (Ufba). Pesquisadora do Centro de Estudos Multidisciplinares em Cultura (Cult-Ufba). Professora do Centro Universitário UniFTC. E-mail: alicepireslacerda@gmail.com. 


\section{RESUMO}

O que pensam os mestres sobre as políticas públicas de cultura desenvolvidas para a capoeira no Brasil? Uma extensa pesquisa de campo buscou conhecer a avaliação que os mestres de capoeira fazem das ações do Estado para a área a partir de suas diferentes condições de participação nas políticas culturais: proponentes de projetos, colaboradores da gestão e participantes de debates públicos. Os resultados mostraram que os mestres de capoeira reconhecem como importantes e necessárias as políticas culturais desenvolvidas para o campo - especialmente as do período entre 2003 e 2010 -, assim como a presença da comunidade da capoeira nos espaços de participação social. Os mestres apontaram ainda a instabilidade e a descontinuidade das políticas, além da falta de efetividade dos resultados da participação social nas ações, como desafios ainda latentes.

Palavras-chave: Políticas culturais. Patrimônio imaterial. Mestres de capoeira. Participação social.

\section{ABSTRACT}

How do capoeira masters perceive the public cultural policies developed for capoeira in Brazil? To understand the assessment of capoeira masters regarding state actions aimed at this art form according to their roles as project proponents, management staff, and participants in public debates on cultural policies, this study performed an extensive field research. The results show that capoeira masters consider the cultural policies developed for the field as important and necessary, especially those implemented between 2003 and 2010, as well as the presence of the capoeira community in spaces of social participation. They also highlighted the instability and discontinuity of policies and the ineffectiveness of social participation in the actions outcomes as latent challenges for the field.

Keywords: Cultural policies. Intangible heritage. Capoeira masters. Social participation. 


\section{INTRODUÇÃo}

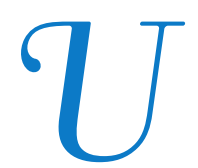

ma das produções culturais afrodiaspóricas mais difundidas no mundo, a capoeira funda-se na corporeidade negra e consolidou-se enquanto resistência ética e estética à escravidão, permanecendo enquanto um aporte epistêmico de enfrentamento ao racismo na sociedade brasileira.

As relações entre poder público e capoeira foram marcadas pelo racismo institucional em nosso país: perseguições, prisões e conflitos foram registrados no período do Brasil Colônia até a década de 1930, quando essa expressão cultural deixou de constar no Código Penal durante o Governo Getúlio Vargas. Apesar disso, a capoeira, assim como outras epistemologias afrodescendentes brasileiras, permaneceu sendo subjugada e menosprezada, sendo considerada uma expressão menor no sistema cultural do país.

A partir da década de 1970, algumas aproximações puderam ser identificadas entre Estado e capoeira no que se refere à tentativa de proposições e ações para o campo, como aquelas que objetivaram a esportivização da prática capoeirística, cujo objetivo era o branqueamento da capoeira a partir de sua marcialização. Outras iniciativas governamentais, mais recentes, travadas a partir dos anos 2000, ocorreram no âmbito das políticas culturais. 
No rol das iniciativas mais recentes do Estado no trato da capoeira no Brasil, destaca-se o reconhecimento como patrimônio imaterial brasileiro em 2008, ação que proporcionou sua nomeação a Patrimônio da Humanidade pela UNESCO em 2014, já que a capoeira é uma das manifestações culturais nacionais mais difundidas pelo mundo - presente em mais de 150 países.

Este artigo se encontra no âmbito das pesquisas sobre a relação entre a capoeira e o Estado brasileiro que estão em crescente desenvolvimento, haja vista a ampla bibliografia sobre o assunto, da qual destacam-se os estudos do campo da história (PIRES, 2001; SOARES, 1993; 2004). A investigação se inclui ainda nas discussões acadêmicas acerca das políticas culturais para a capoeira no país, cujo foco principal tem sido o processo de sua patrimonialização a partir de 2008; porém, observa-se uma lacuna no que diz respeito às pesquisas que avaliam a eficácia das políticas culturais desenvolvidas para a capoeira a partir da ótica dos seus públicos assistidos, mais especificamente dos mestres de capoeira.

Os resultados apresentados neste artigo fazem parte de uma pesquisa mais ampla sobre políticas culturais para a capoeira no Brasil2 2 . O presente texto limita-se a discutir a percepção dos mestres quanto à sua participação nas políticas públicas de cultura desenvolvidas para a capoeira. A investigação voltou-se apenas às políticas culturais desenvolvidas no âmbito federal, mesmo que algumas delas tenham envolvido gestões estaduais ou municipais na sua realização. Quanto ao espaço e a temporalidade, as políticas culturais abordadas no texto são de abrangência nacional, embora sejam avaliadas a partir do desenvolvimento nos respectivos estados e municípios e ao período entre 2000 e 2015.

A problemática da pesquisa buscou apurar como ocorreram as participações dos mestres nas políticas culturais federais para a

2 A autora se refere à investigação desenvolvida durante seu doutoramento que envolveu uma pesquisa de campo realizada entre os anos de 2014 e 2015, na qual foram entrevistados 33 mestres de capoeira em quatro estados brasileiros (Bahia, Rio de Janeiro, São Paulo e Pernambuco) e no Distrito Federal (Brasília). 
capoeira e como os entrevistados perceberam essa experiência de interlocução com representantes do poder público. Optou-se por uma pesquisa de caráter descritivo e abordagem qualitativa, com procedimentos metodológicos de pesquisa bibliográfica e pesquisa de campo, quando foram realizadas entrevistas semiestruturadas. O critério para escolha dos mestres entrevistados na pesquisa foi seu envolvimento em algum espaço de participação em políticas públicas para a capoeira, sendo a participação no Conselho de Mestres o critério que prevaleceu para a realização de viagens a outros estados e ao Distrito Federal. Observou-se na amostragem selecionada a ocorrência de três principais condições de participação entre os mestres entrevistados, sendo elas: proponentes de projetos aprovados pela gestão pública para fins de apoio financeiro; colaboradores da gestão pública, como consultores ou pareceristas; e participantes de debates públicos, presentes em reuniões, encontros, conferências etc. promovidos pelo poder público para discutir ações para a capoeira.

\section{POLÍTICAS CULTURAIS, PARTICIPAÇÃO SOCIAL E CAPOEIRA}

Em "Políticas Culturais entre o possível e o impossível", Albino Rubim (2006) propõe pensar a abrangência das políticas culturais, elencando e analisando os componentes de uma ação digna de tal definição. Entre as categorias que precisam ser analisadas em uma política cultural, o autor destaca a necessidade de delimitar e caracterizar os atores sociais nela envolvidos. Ainda segundo Rubim (2006), para além do Estado, as políticas culturais contemporâneas envolvem "um conjunto complexo de atores" públicos e privados, apresentando-se como o resultado da interação entre governos nacionais, supranacionais, infranacionais, organizações privadas e sociedade civil. O autor salienta que o debate sobre políticas culturais converge para uma discussão acerca do entendimento de política pública e participação social: 
Na perspectiva das políticas públicas, a governança da sociedade, na atualidade, transcende o estatal, impondo a negociação como procedimento usual entre os diferentes atores sociais. Somente políticas submetidas ao debate e crivo públicos podem ser consideradas substantivamente políticas públicas de cultura. Tal negociação, entretanto, é sempre bom lembrar, acontece entre atores que detêm poderes desiguais e encontram-se instalados de modo diferenciado no campo de forças que é a sociedade capitalista contemporânea. Assim, políticas públicas de cultura podem ser desenvolvidas por uma pluralidade de atores político-sociais, não somente o Estado, desde que tais políticas sejam submetidas obrigatoriamente a algum controle social, através de debates e crivos públicos. (RUBIM, 2006, p. 11)

A percepção de Rubim sobre o conceito de política pública aplicado às políticas culturais evoca a noção de "democracia cultural", conhecida também por "cidadania cultura" (CHAUÍ, 2006), que compreende o direito da população à cultura não apenas no âmbito do acesso e consumo, mas também nas esferas da produção cultural, bem como nas de formulação, execução e avaliação das ações voltadas à cultura. Sob essa perspectiva, a participação social é incentivada e fomentada pelo poder público enquanto premissa de gestão cultural que prioriza a efetivação e eficácia das ações realizadas.

Percebida como direito, a participação social na perspectiva da democracia cultural se insere no que Gohn (2003) denomina "democracia deliberativa", sistema que articula princípios da democracia direta e da democracia representativa. O modelo deliberativo defendido por Gohn (2003) "diz respeito aos mecanismos de representação política, em que existe o envolvimento dos indivíduos como cidadãos políticos ativos em diálogos interativos realizados no decorrer do processo de participação e na elaboração de políticas públicas” (SIMÕES; SIMÕES, 2015, p. 9). 
Entre os anos de 2003 e 2010, o Estado brasileiro, sobretudo na esfera federal, buscou desempenhar o papel de mediador na construção de consensos, possibilitada pela ampliação da participação social, quanto às prioridades das políticas culturais no país e seu processo de efetivação por meio da gestão do Ministério da Cultura (MinC) (RUBIM, 2008). Isso transcorreu também no que se refere às políticas voltadas à capoeira naquele período, incidindo sobre tentativas de constituição de redes de atores sociais do campo, o que, em alguns momentos, incluiu os mestres de capoeira.

Com objetivo de incorporar a sociedade civil à gestão das políticas públicas para a capoeira, como ocorreu com o Projeto Capoeira Viva ${ }^{3}$, ou mesmo dar sustentabilidade às ações, a participação social dos mestres esbarrou em entraves, dificuldades e conflitos, como pode ser verificado a partir da análise das falas dos mestres entrevistados.

\section{MESTRES DE CAPOEIRA E A INTERLOCUÇÃO COM 0 ESTADO NA CONDIÇÃO DE PROPONENTES DE PROJETOS}

Os mestres entrevistados relataram sua participação como proponentes de projetos aprovados em seleção pública do MinC e suas autarquias, experiências que envolveram também a gestão desses projetos. No grupo de mestres que concorreram com seus projetos em seleções públicas por edital, Mestre Toni Vargas ${ }^{4}$ conseguiu, por duas vezes, aprovar seus projetos no âmbito do Projeto Capoeira Viva, iniciativa que ele avaliou positivamente:

3 O Projeto Capoeira Viva foi uma ação integrante do Programa Brasileiro e Mundial da Capoeira (2005) desenvolvido pelo MinC entre 2006 e 2015 com intuito de fomentar a implementação de políticas públicas para a valorização e promoção da capoeira como bem constituinte do patrimônio cultural brasileiro. A primeira fase do projeto foi gerida pela Associação de Apoio ao Museu da República no Rio de Janeiro (2006 -2007), e a segunda fase, pela Fundação Gregório de Matos em Salvador (2007-2015), tendo como principal estratégia o repasse de recursos públicos para projetos selecionados através de editais públicos.

4 Antônio César de Vargas é mestre de capoeira do Grupo Senzala desde 1985 e fundador do Centro Cultural Senzala, na cidade do Rio de Janeiro. 
No primeiro momento, o próprio Capoeira Viva, de alguma maneira, surpreendeu os capoeiristas. No início dele, pela relativa simplicidade - é claro que, ainda assim, teve dificuldades enormes, para vários capoeiristas - e pela funcionalidade dele, que está ligado a essa simplicidade. (Mestre Toni Vargas, informação verbal, 2014)

Mestre Toni Vargas relatou que, assim como ele, muitos outros mestres e grupos de capoeira foram selecionados pelo projeto e que, para a maioria, tratou-se de uma experiência nova. Na avaliação de Mestre Toni Vargas, as principais dificuldades encontradas se referiram à prestação de contas, já que eles não tiveram orientação sobre como deveriam comprovar as despesas realizadas.Crítico quanto à condução do ministério no Capoeira Viva, Mestre Moraes também foi proponente de projeto selecionado por edital do projeto, contando algumas das dificuldades encontradas ao gerir seu projeto:

Eles não procuram [se] atentar ao fato de que o mestre de capoeira, ou seja, as pessoas que lidam com manifestações culturais, elas não têm a condição de atender aos trâmites burocráticos que eles impõem a você, caso você queira uma fatia do bolo. (Mestre Moraes, informação verbal, 2015)

Podemos perceber na fala de Mestre Moraes $^{5}$ uma queixa quanto à falta de sensibilidade do órgão em compreender o público para o qual são direcionados os editais e a ausência de assessoramento institucional do ministério no sentido de orientar os proponentes na realização dessa prestação de contas.

Além de ter sido a primeira experiência de gestão para muitos mestres de capoeira, o Ponto de Cultura foi também um desafio de gestão para o próprio ministério, pois foram os primeiros editais voltados para projetos realizados por um público da cultura que, historicamente,

5 Pedro Moraes Trindade é considerado um dos responsáveis pelo movimento de revalorização da Capoeira Angola, iniciado nos anos de 1980, década na qual fundou o Grupo de Capoeira Angola Pelourinho (GCAP) em Salvador, Bahia. 
desconhecia esses meios de acesso aos recursos públicos. A reclamação da falta de assessoramento institucional do ministério na execução do projeto também foi lembrada por Mestre Curió:

Outra coisa, lhe dá o ponto de cultura, você ganha o ponto de cultura pelos seus méritos, mas eles não dão um setor jurídico, uma organização jurídica para dizer: "Você vai gastar o dinheiro assim, isso pode e isso não pode”. (Mestre Curió, informação verbal, 2015)

Ao analisar as políticas para a capoeira, Costa (2013) se atenta para um nível desproporcional de "cobranças e exigências" por parte do Estado com relação aos proponentes dos projetos apoiados, que, além de desconsiderar sua inexperiência, não ofereceu acompanhamento nem orientações compatíveis com o que era exigido. Além do mais, o autor constatou "problemas de gestão destas políticas também em sua execução”, ou seja, o Estado cobrou aquilo que ele mesmo não realizou, pois demonstrou "incapacidade de gerir verbas e de prestar contas" (COSTA, 2013, p. 312).

A inexperiência dos proponentes e os problemas enfrentados pelo MinC na condução dos projetos revelam mais do que um problema de gestão pública, pois se apresentam como sintomáticos em uma sociedade de classes na qual o Estado representa os interesses de poucos. Portanto, como já foi analisado em pesquisas anteriores (LACERDA, 2010), experiências como o Cultura Viva expõem a necessidade de democratização do Estado, com a criação, manutenção e ampliação das arenas de participação popular em suas políticas que questionem e pressionem o poder público a criar caminhos e condições de apropriação de seus serviços pela população.A falta de continuidade das ações ou mesmo da instabilidade institucional foi outra ocorrência mencionada por alguns mestres. Mestre Itapoan criticou a falta de continuidade da política, já que um terceiro edital no âmbito do Projeto Capoeira Viva estava previsto para ocorrer e foi suspenso. A instabilidade institucional 
do órgão responsável pela gestão da segunda etapa do projeto contribuiu para a sua descontinuidade, conforme declarou Mestre Itapoan ${ }^{6}$ :

Durante esse período, a Fundação Gregório de Mattos ganhou três presidentes. Era coisa política, o João Henrique tirou um e botou outro na prefeitura e pronto, e cada um que chegava tem que tomar pé de cada um do que está rolando, então, está aí [...]. (Mestre Itapoan, informação verbal, 2014)

A alternância de gestores da Fundação Gregório de Mattos, em um curto período, segundo Mestre Itapoan, aprofundou os entraves enfrentados pelo projeto devido aos problemas nas prestações de contas de alguns projetos. A essa fase de instabilidade institucional no órgão gestor do projeto, sucedeu-se a mudança para o Governo Dilma, com a ministra Ana de Holanda assumindo o MinC, conjuntura que paralisou a iniciativa.

A falta de continuidade do Projeto Capoeira Viva ocorreu não apenas na mudança de um governo para o outro (Lula para Dilma), mas dentro do próprio Governo Lula. Para Calabre (2014), entre os anos de 2007 e 2010 - período que coincide com a execução da segunda etapa do Projeto Capoeira Viva -, um balanço das ações implementadas pelo MinC apontava para o fato de que "uma série de novas portas foram abertas sem que as anteriores fossem fechadas, ou melhor, sem que as inovações propostas tivessem obtido algum grau de efetividade" (2014, p. 155). A abertura de novos ciclos de ações sem o devido fechamento de ciclos anteriores acarretou a ampliação das dificuldades de efetivação da política cultural pretendida.

Ainda conforme avaliação de Mestre Itapoan, o encerramento das atividades do projeto não significou a desmobilização da política,

6 Raimundo César Alves de Almeida nasceu em 1947, em Salvador, cidade onde desenvolve seu trabalho de capoeira através da Ginga Associação de Capoeira, no Brasil e no exterior.

7 João Henrique Carneiro foi Prefeito da cidade de Salvador, nos períodos 2005-2008 (PDT) e 2009-2012 (PMDB). 
e os capoeiristas continuaram cobrando respostas das instituições. Mestre Itapoan criticou o modo como as políticas foram "abandonadas" pelas gestões: sem a apresentação de um balanço do que foi realizado, discriminando os recursos destinados e disponibilizando ao acesso público as informações e produtos resultantes das ações empreendidas. Segundo o mestre, a falta de transparência na atuação do Estado e de sistematização de resultados contribuiu para as avaliações negativas das políticas e para a ratificação do descrédito no poder público.

Assim como Mestre Itapoan, a pesquisa de Costa (2013) constatou uma ausência de sistematização e disponibilização de informações, conteúdos e produtos resultantes de projetos voltados para a capoeira no âmbito das políticas culturais do Governo Lula. Para o autor, as gestões pecaram nesse sentido, sendo que grande parte de tudo que se produziu nesse contexto ficou no desconhecimento da comunidade da capoeira.

Nesse sentido, Calabre (2014) também teceu críticas e ressaltou que "a preocupação com a produção e sistematização de informações sobre as próprias ações do MinC eram praticamente inexistentes" até o Governo Lula, e que, mesmo sendo uma questão colocada pelas duas gestões desse governo, as "tentativas de levar a questão adiante, promovendo ações efetivas, sofreram processos de descontinuidade e de baixo grau de investimento" (2014, p. 145-146). Percebe-se que as gestões Gil e Juca à frente do MinC mobilizaram novos atores políticos, criando "expectativa da efetividade da implantação de novos modelos de gestão das políticas culturais" (CALABRE, 2014, p. 156). Apesar disso, a ruptura das ações em curso colocou em xeque a credibilidade das instituições públicas e, no que tange à capoeira, esse recente episódio da relação com o Estado contribuiu para reforçar o aguçado senso de desconfiança dos capoeiristas. 


\section{PARTICIPAÇÃO COMO COLABORADORES NA GESTÃO DA POLÍTICA PÚBLICA}

\section{PARA A CAPOEIRA}

Uma outra condição de participação em políticas públicas relatada pelos mestres entrevistados foi a de colaborador da gestão pública como membro do Conselho de Mestres do Projeto Capoeira Viva, um grupo criado informalmente pela gestão da política para atuar como consultor no desenvolvimento de suas ações. Esse conselho foi composto por dez membros, entre os quais sete foram entrevistados nessa pesquisa: Itapoan (BA), Moraes (BA), Camisa (RJ), Burguês (RJ), Zulu (DF), Suassuna (SP) e Mestra Janja (BA).

Perguntado sobre qual tinha sido a função do Conselho de Mestres do Capoeira Viva, Mestre Camisa ${ }^{8}$ respondeu: "Indicar algumas coisas, informar, esclarecer algumas coisas. Eu fui a Brasília algumas vezes, indicando principalmente os mestres mais velhos, da velha guarda" (Mestre Camisa, informação verbal, 2014). $\mathrm{Na}$ fala do mestre, podemos perceber uma confirmação do caráter consultivo do conselho e uma referência à indicação de nomes de velhos mestres de capoeira. O conselho foi responsável por indicar cinquenta nomes de velhos mestres para compor uma Academia de Mestres de Capoeira, uma ação de reconhecimento do trabalho dessas pessoas e de apoio financeiro a esses mestres, promovida pelo projeto.

A avaliação de Mestre Camisa sobre a insuficiência da atuação do conselho durante as gestões de Gilberto Gil e Juca Ferreira à frente do ministério reverberou na fala dos demais mestres, assim como a paralisação de suas atividades após a mudança de gestão do projeto para a Fundação Gregório de Mattos e, posteriormente, a interrupção da política com a posse da ministra Ana de Holanda.

8 José Tadeu Carneiro Cardoso nasceu em Jacobina, município do estado da Bahia, em 1955. A partir de 1972, estabeleceu-se no Rio de Janeiro, onde integrou o Grupo Senzala até 1988, quando fundou a Associação Brasileira de Apoio e Desenvolvimento da Arte Capoeira (A.B.A.D.A Capoeira), que lidera atualmente. 
De maneira geral, os mestres e a mestra entrevistados que participaram do Conselho de Mestres do Projeto Capoeira Viva consideraram suas participações tímidas e pontuais, com a realização de um número baixo de reuniões - ninguém soube precisar quantas -, sendo, na opinião deles, muito pouco requisitados pela gestão da iniciativa. As reuniões para a indicação dos nomes dos velhos mestres de capoeira, que comporiam a Academia de Mestres e receberiam o apoio financeiro do programa, foram citadas quase que como a única atividade desse conselho.

Segundo pesquisa realizada por Costa (2013), a formação da Academia de Mestres foi o que motivou o coordenador do projeto a criar o conselho, porém, o autor especula que sua gestão tinha esperanças de que ele ganhasse maiores dimensões e que, assim, o conselho ganharia importância, enquanto instância consultiva e legitimadora da política. O autor concluiu que esse desdobramento não ocorreu e, confirmando o prognóstico dos mestres entrevistados, a indicação dos nomes que comporiam a Academia de Mestres se configurou como única ação do coletivo.

Ainda sobre o conselho, Mestre Moraes teceu críticas à gestão do projeto e à atuação desse grupo de mestres. Para ele, sua criação foi uma estratégia para dar uma conotação democrática às suas resoluções, sendo que a sua participação no conselho foi mais formal do que efetivamente consultiva.

Embora Mestre Moraes qualifique sua participação no conselho como "mera formalidade", Costa (2013) constatou não haver nenhum registro oficial de sua existência nem de suas atividades, ou mesmo registro do conteúdo das reuniões. Logo, esse conselho atuou informalmente, representando "uma ação da coordenação da primeira gestão do PGV, que possuía autonomia para tal” (p. 122), não tendo continuidade na segunda etapa do projeto sob a nova gestão.

Para Costa (2013), os processos de elaboração e implementação de políticas públicas para a capoeira demandam a existência e a 
atuação de um Conselho de Mestres permanente, "onde os seus membros tenham uma alternância constante e representatividade ampliada, por todo o território nacional, estabelecendo formas de desenvolvimento e continuidade das ações” (p. 296).

Ainda no grupo de participação como colaboradores da gestão pública, alguns mestres atuaram como consultores e pareceristas. Mestra Janja ${ }^{9}$, que, além de ter atuado como conselheira do Cultura Viva, foi também parecerista de projetos submetidos aos processos seletivos do programa, destacou a seriedade das gestões Gilberto Gil e Juca Ferreira, à frente do MinC e na condução das políticas de cultura para a capoeira, sendo esse um motivo preponderante para sua colaboração nessa política.

\section{PARTICIPAÇÃO dOS MESTRES DE CAPOEIRA EM DEBATES PÚBLICOS}

Muitos dos mestres entrevistados relataram suas atuações como participantes em debates públicos, como encontros, seminários, conferências e reuniões, promovidos pelos poderes públicos para discutir políticas para a capoeira. Mestre Pêu $u^{10}$ afirmou participar de conferências municipais já há algum tempo e criticou a falta de interesse dos capoeiristas em participar desses momentos.

Essa falta de interesse dos capoeiristas nas conferências setoriais, apontada por Mestre Pêu, alinha-se ao que Faria (2005) chamou de "desencantamento da política", que atinge os processos participativos devido à "participação pífia e com resultados discutíveis em relação a mudanças" (p. 115). Segundo o autor, os processos participativos como conferências e conselhos ainda sofrem muito controle estatal e apresentam baixo grau de autonomia, além de

9 Rosângela Costa Araújo, nascida em 1960 em Feira de Santana (BA), iniciou-se na capoeira na década de 1980 e fundou em 1995 o Grupo Nzinga de Capoeira Angola, com atividades em Salvador, São Paulo, Brasília e Maputo, Moçambique

10 Pedro Luís da Silva nasceu em Recife, em 1965, e começou a jogar capoeira em 1975. Hoje desenvolve seu trabalho de capoeira à frente do Grupo Quilombo, na periferia de Recife, Pernambuco. 
outros problemas, como o nível de representatividade dos membros participantes e da reiterada prática de clientelismo por parte dos poderes públicos.

As conferências, enquanto espaços de participação cidadã, são conquistas ainda muito recentes da democracia brasileira que vêm se firmando no campo das disputas políticas e sociais do país, o que implica no nível e qualidade da representatividade, bem como da sua autonomia.

A desconfiança dos capoeiristas com relação às conferências e demais eventos se fundamenta na observação de práticas como o clientelismo e a cooptação de representantes, apontadas por Faria e Moreira (2005), ou mesmo no fato das gestões culturais interagirem sempre "com os mesmos atores das elites culturais locais; alguns estimulam novos espaços e ações culturais, mas sem capilaridade massiva e permanente nos bairros mais distantes" (2005, p. 12) ou nas bases sociais das expressões culturais.

Faria e Moreira (2005) defendem a importância de modos alternativos de gestão cultural, nos quais a participação "da sociedade civil na política cultural pode torná-la plural, humanizar relações, mudar as práticas arraigadas do corporativismo, formatar um projeto político-cultural de prosperidade material e espiritual junto com a localidade" (2005, p. 14). Para os autores, ao compartilhar decisões, os diferentes atores sociais estão socializando saberes e quereres, produzindo um aprendizado do exercício democrático entre os diferentes que são unidos pela igualdade da participação política e da decisão coletiva.

Para Mestre Corisco ${ }^{11}$, sua participação em eventos dessa natureza representa, antes de tudo, o seu papel como cidadão de participar e contribuir na vida pública do seu país, ou seja, um dever cívico. Além disso, declarou assumir uma postura política nessas participações:

11 José Olímpio Ferreira da Silva teve seu primeiro contato com capoeira no final da década de 1970 e fundou, junto ao Mestre Birilo, o Grupo Chapéu de Couro de Capoeira, em 1983, em Recife, Pernambuco, onde dá aulas atualmente. 
Quando eu vou para essas reuniões de políticas públicas, eu tento me colocar de forma política também. E de forma que eu deixo claro que existe uma política pública, mas que não precisa depender de um partido e que um partido pode exercitar essa política pública, mas que a gente não pode depender de instituição política, nem de partido político. (Mestre Corisco, informação verbal, 2014)

Percebemos, na declaração de Mestre Corisco, clareza quanto aos diferentes tipos de participação que o cidadão pode e deve exercer na vida política do seu país ou localidade. Para o mestre, a participação em espaços e instâncias de interlocução com a gestão pública e com uma política pública não está relacionada a uma atuação político-partidária. Por outro lado, a execução de uma política pública não precisa depender de uma gestão ou partido político específicos, como é o caso das políticas de Estado.

Para Faria e Moreira (2005), a participação na cultura e a cultura da participação constituem um binômio fundamental à formação cultural de cidadãos, ativos e inventivos, que sejam capazes de "assegurar a continuidade dos projetos significativos para a sociedade, a moralização da coisa pública, a gestão transparente e ética, a formação de comunidades vigilantes dos direitos conquistados, a difusão da criação e a fruição cultural nos espaços públicos" (2005, p. 14).

Além da pluralidade de possibilidades de participação política, Mestre Corisco esclareceu que contribuir ou participar de determinada política pública não significa compactuar com nenhum partido ou gestão pública em particular:

A gente pode até trabalhar junto com a prefeitura, mas a prefeitura precisa entender que a gente pode até cooperar com aquela gestão, pela conveniência, mas que a política pública da capoeira é uma coisa, vamos dizer, atemporal e adimensional [...]. (Mestre Corisco, informação verbal, 2014) 
Mais uma vez, Mestre Corisco ratificou o caráter transcendental das políticas públicas em relação às gestões por entender que a participação da sociedade civil, por meio de instâncias públicas, não compromete sua autonomia frente ao poder público ou a qualquer gestão pública.

O exercício de cidadania, representado pela participação política e defendido por Mestre Corisco, além de constituir-se como um direito dos cidadãos, se apresenta como um instrumento de aprimoramento da política pública. Assim, a qualidade da política pública de cultura está estritamente relacionada ao grau de participação política da população, desde que essa participação tenha entre seus objetivos aqueles capazes de tornar a política acessível a mais pessoas, otimizar os recursos públicos, controlar os gastos públicos, entre outros (TEIXEIRA, 2005).

O processo de inventário e registro da capoeira como patrimônio imaterial do Brasil foi um assunto abordado por Mestre Pinatti ${ }^{12}$, que avaliou que o processo que culminou no registro da capoeira como Patrimônio Imaterial do Brasil, ocorreu sem o conhecimento dos mestres:

Eles [o Iphan] teriam que consultar a gente primeiro, nós somos donos. Tombou não foi o atabaque, pandeiro e berimbau - que é coisa -, somos nós, seres humanos, os mestres de capoeira. Então, tinham que consultar a gente, foi à nossa revelia. (Mestre Pinatti, informação verbal, 2014)

Costa (2013) reforça em sua pesquisa essa ausência de escuta dos capoeiristas no processo de registro da capoeira, constatando um número inexpressivo de assinaturas no termo de anuência que acompanhou o inventário. ${ }^{13}$

As reclamações dos entrevistados quanto à ausência de escuta na relação com o Estado fazem parte de um conjunto de demandas reprimidas historicamente pela sociedade brasileira, no gozo dos

12 Djmair Pinatti nasceu em 1930 em Orlândia (SP), filho de imigrantes italianos iniciou-se na capoeira em 1962 e fundou a Associação de Capoeira São Bento Pequeno, juntamente com Mestre Limão, em funcionamento até os dias de hoje, na capital paulista.

13 O autor informou 96 assinaturas (COSTA, 2013). 
seus poucos anos de regime democrático. No que se refere à política de patrimônio imaterial, a novidade é ainda maior, já que o decreto $^{14}$ que a instaura no país data de 2000, o que não coincide com a sua efetiva implementação, ainda mais recente.

Nesse sentido, as instituições públicas brasileiras ainda estão em processo de implantação e aprimoramento das esferas de escuta e participação da sociedade civil, tendo sofrido um duro golpe durante o Governo Bolsonaro, que extinguiu e alterou os canais de participação social nas políticas públicas através do Decreto Federal $\mathrm{n}^{\circ} 9.759$ (BRASIL, 2019).

\section{CONSIDERAÇÕES FINAIS}

Observou-se uma pluralidade de condição e espaço de participação dos mestres entrevistados nas políticas culturais para a capoeira, o que pode ser interpretado como uma mudança histórica significativa na condução da gestão pública de cultura ao estimular, criar e manter meios para efetivação da participação da comunidade de capoeira.

Para os mestres que participaram das políticas culturais como proponentes de projetos, a experiência representou uma novidade, pois grande parte não havia vivenciado uma interlocução com as instituições do Estado. Observou-se que parte dos problemas enfrentados pelos mestres na condução de seus projetos culturais se deveu a essa inexperiência e à falta de informações, orientação e acompanhamento do poder público.

Essa inexperiência - também observada nos gestores públicos mais uma vez catalisou problemas na execução da política, sendo os processos de prestação de contas dos projetos sintomáticos nesse sentido. Observou-se um alto nível de exigência burocrática por parte do poder público, incompatível com a disponibilidade de

14 Decreto $n^{\circ} 3551$, de 4 de agosto de 2000, que instituiu o Registro de Bens Culturais de Natureza Imaterial e criou o Programa Nacional do Patrimônio Imaterial (BRASIL, 2000). 
orientação e acompanhamento que se deveria oferecer aos proponentes, demonstrando desconhecimento quanto ao funcionamento do próprio Estado.

Além da falta de acompanhamento, a descontinuidade e a interrupção da política sem uma conclusão oficial, causada pela instabilidade institucional do órgão gestor, foi um outro aspecto criticado pelos mestres entrevistados. Os entrevistados interpretam essa postura da gestão como uma despreocupação em prestar contas à sociedade, quanto ao retorno do investimento de recursos públicos, o que desestimula a participação em iniciativas futuras do poder público.

A participação dos mestres enquanto colaboradores da gestão pública demonstrou algum tipo de abertura política do poder público, que criou as condições para que essa participação ocorresse. O Conselho de Mestres do Capoeira Viva mostrou a vontade dos mestres em participar das decisões que envolviam a gestão da política, bem como a de colaborar com seu conhecimento e experiência para uma melhoria do campo. Além disso, a atuação do conselho poderia ter representado uma maior legitimidade e credibilidade da ação do poder público junto à comunidade de capoeira, cobrando dos órgãos gestores resultados das ações empreendidas. A baixa participação dos capoeiristas em espaços de interlocução com o Estado, como as conferências setoriais, demonstram um desencantamento com a política, explicado por um certo sentimento de ineficiência dessa participação, causado pela ausência de resultados imediatos que representem mudanças na realidade das pessoas. Por isso a participação dos cidadãos na gestão pública de cultura deve visar pluralizar a gestão, aproximando-a da diversidade cultural de públicos e expressões, agindo também na humanização das relações, inclusive entre as instituições públicas e os cidadãos. Além do mais, a participação social deve se constituir também enquanto uma partilha de poder, de forma que ele não seja um monopólio do Estado. 
A cultura da participação se apresenta como um caminho para a consolidação de uma democracia cultural na qual o envolvimento dos cidadãos nas políticas públicas de cultura evolua para sua apropriação. Quando os cidadãos "tomam as rédeas" da política cultural, são maiores e melhores as chances para sua continuidade, existindo condições de controle e pressão dos órgãos públicos diante das alternâncias de gestão. Nesse contexto de apropriação cidadã da política, podemos pensar e realizar uma proposta de gestão para a capoeira que transcenda a gestão partidária e se coloque de maneira mais autônoma e política.

\section{REFERÊNCIAS}

BRASIL. Decreto ${ }^{\circ}$ 3.551, de 4 de agosto de 2000. Institui o registro de bens culturais de natureza imaterial que constituem patrimônio cultural brasileiro, cria o Programa Nacional do Patrimônio Imaterial e dá outras providências. Diário Oficial da União, Brasília, DF, 7 ago. 2000.

BRASIL. Decreto n ${ }^{\circ} 9.759$, de 11 de abril de 2019. Extingue e estabelece diretrizes, regras e limitações para colegiados da administração pública federal. Diário Oficial da União, Brasília, DF, 11 abr. 2019.

CALABRE, L. Política cultural em tempos de democracia: a Era Lula. Revista do Instituto de Estudos Brasileiros, São Paulo, n. 58, p. 137-156, 2014.

CHAUÍ, M. Cidadania cultural. São Paulo: Editora Fundação Perseu Abramo, 2006.

COSTA, N. L. Capoeira, política cultural e educação. 2013. Tese (Doutorado em Educação) - Faculdade de Educação, Universidade Federal da Bahia, Salvador, 2013.

FARIA, H. Conselhos municipais de cultura e cultura participativa: reavaliar caminhos e buscar horizontes. In: FARIA, H.; MOREIRA, A.; VERSOLATO, F. (org.). Você quer um bom conselho? Conselhos municipais de cultura e cidadania cultural. São Paulo: Instituto Pólis, 2005. p. 114-122. 
FARIA, H.; MOREIRA, A. Cultura e governança: um olhar transversal de futuro para o município. In: FARIA, H.; MOREIRA, A.; VERSOLATO, F. (org.). Você quer um bom conselho? Conselhos municipais de cultura e cidadania cultural. São Paulo: Instituto Pólis, 2005. p. 9-18.

GOHN, M. G. Conselhos gestores e participação sociopolítica. São Paulo: Cortez, 2003.

LACERDA, A. P. Políticas públicas de cultura para a democracia cultural: uma análise do Programa Cultura Viva do Ministério da Cultura. 2010. Dissertação (Mestrado em Cultura e Sociedade) - Faculdade de Comunicação, Universidade Federal da Bahia, Salvador, 2010.

PIRES, A. L. C. S. Movimentos da cultura afro-brasileira: a formação histórica da capoeira contemporânea 1890-1950. 2001. Tese (Doutorado em História) - Instituto de Filosofia e Giências Humanas, Universidade Estadual de Campinas, Campinas, 2001.

RUBIM, A. A. C. Políticas culturais entre o possível e o impossível. In: ENCONTRO DE ESTUDOS MULTIDISCIPLINARES EM CULTURA, 2., 2006, Salvador. Anais [...]. Salvador: Ufba, 2006.

RUBIM, A. A. C. Políticas culturais do Governo Lula/Gil: desafios e enfrentamentos. Revista Brasileira de Ciências da Comunicação, São Paulo, v. 31, n. 1, p. 183-203, 2008.

SIMÕES, G. L.; SIMÕES, J. M. Reflexões sobre o conceito de participação social no contexto brasileiro. In: JORNADA INTERNACIONAL POLÍTICAS PÚBLICAS, 7., 2015, São Luís. Anais [...]. São Luís: Ufma, 2015.

SOARES, C. E. L. A capoeira escrava e outras tradições rebeldes no Rio de Janeiro 1808-1850. 2. ed. Campinas: Editora da Unicamp, 2004.

SOARES, C. E. L. A negregada instituição: os capoeiras no Rio de Janeiro 1850-1890. 1993. Dissertação (Mestrado em Filosofia) - Instituto de Filosofia e Ciências Humanas, Universidade Estadual de Campinas, Campinas, 1993.

TEIXEIRA, A. C. Formação dos conselhos no Brasil. In: FARIA, H.; MOREIRA, A.; VERSOLATO, F. (org.). Você quer um bom conselho? Conselhos municipais de cultura e cidadania cultural. São Paulo: Instituto Pólis, 2005. p. 19-26. 